\section{Unintended pregnancy with subdermal implant following miscarriage: response to Rank letter}

Thank you for publishing Dr Rank's report of an unintended pregnancy with a subdermal implant following a miscarriage. ${ }^{1}$ While I agree with much of Dr Melvin's response on behalf of the Clinical Effectiveness Unit, ${ }^{2}$ I think fundamentally the case highlights that continued reliance on apparent menstrual dates is flawed. Ultrasound dating of pregnancy has provided strong evidence that menstrual dates are frequently a poor guide to ovulation and conception timing. For this reason reliance on menstrual dates has largely been abandoned in obstetric practice. Surely it is time to review and revise guidance that relies on menstrual dates in contraceptive practice. While there is no practical tool for assessing how close to ovulation an individual woman may be, it is essential to continue taking and recording a menstrual history. However, appropriate counselling should inform women that it is not possible to detect a pregnancy for 3 weeks after conception and the elements of uncertainty predicting safety when starting to rely on any new method. The message that stopping or switching any method is a high-risk time for unintended pregnancy should become embedded in contraceptive information to women. Where there is any scope for doubt the best advice is to do or repeat a pregnancy test 3 weeks after commencing a new method. 'Quick start' is a sound strategy for minimising unintended pregnancy, but advice about the risk of pregnancy and the need to exclude this retrospectively should be routine.

The second problem the case highlights is the continuing lack of quality assurance in services providing early pregnancy ultrasound. If the patient was 13 weeks 1 day exactly 13 weeks after the original scan, which reported an intrauterine gestation sac, then Dr Rank is correct in concluding she was already 
pregnant when the implant was inserted. There cannot have been a gestation sac 2 weeks before the likely conception date of this pregnancy. What was reported as a gestation sac was likely a collection of fluid within the endometrial cavity or 'pseudo sac'. The ultrasound criteria for differentiating an early intrauterine pregnancy from a 'pseudo sac' were reported 30 years ago. Definitive diagnosis of an intrauterine pregnancy includes visualisation of a yolk sac or embryo within the sac. It seems likely that failure to observe these criteria resulted in misinterpretation of the subsequent scan as confirmatory of miscarriage. This fundamentally undermined the assessment for the implant fitting.

Mary Pillai, FRCOG, MRCPCH

Consultant in Community Gynaecology and Obstetrics, NHS Gloucestershire - Sexual Health

Service, Gloucester, UK; mary.pillai@glos.nhs.uk

Competing interests None.

J Fam Plann Reprod Health Care 2012;38:140-141. doi:10.1136/jprhc-2012-100315

\section{References}

1 Rank K. Unintended pregnancy with subdermal implant following miscarriage. J Fam Plann Reprod Health Care 2012;38:65

2 Melvin L. Unintended pregnancy with subdermal implant following miscarriage: response from the CEU. J Fam Plann Reprod Health Care 2012;38:65-66. 